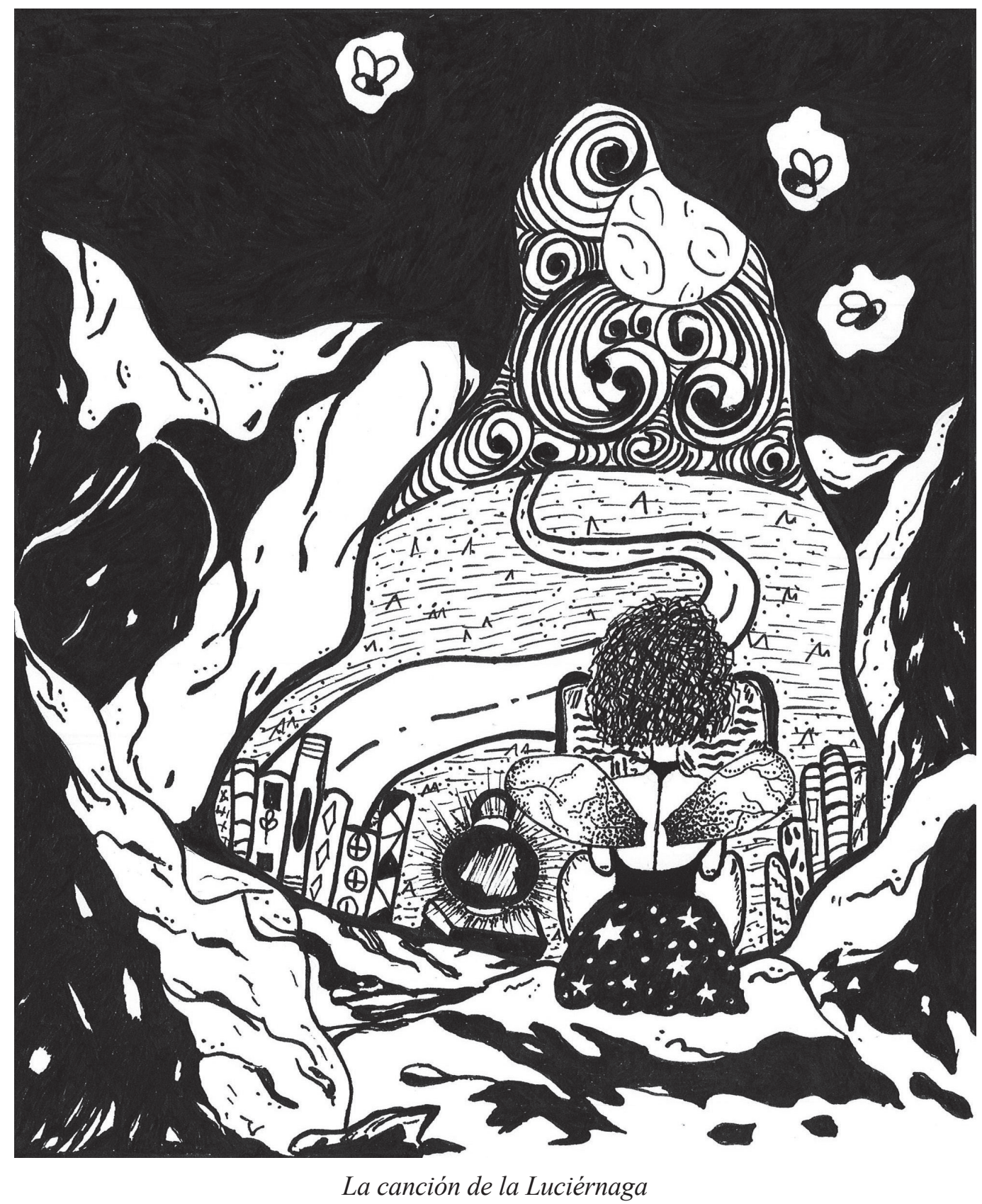

Kimberly Villegas Alpízar

Técnica: plumilla y tinta, 2018.

Ilustra la canción

La canción de la Luciérnaga 



\section{La canción de la Luciérnaga}

Secuela paralela de El vals del Coyote (Max Góldenberg)

Esdrujolúdico

Daniel Solano Ulate

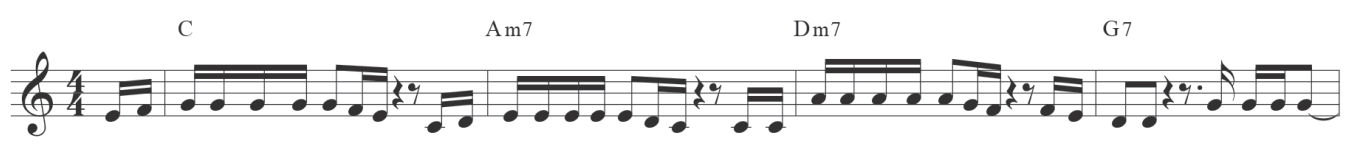

No soy na-da claus-tro-fó-bi-ca, ra-ras ve-ces fo-to-gé-ni-ca. Soy hu - ra-ña me-lan-có-li-ca, ni pa-rez-co u - na lu-ciér

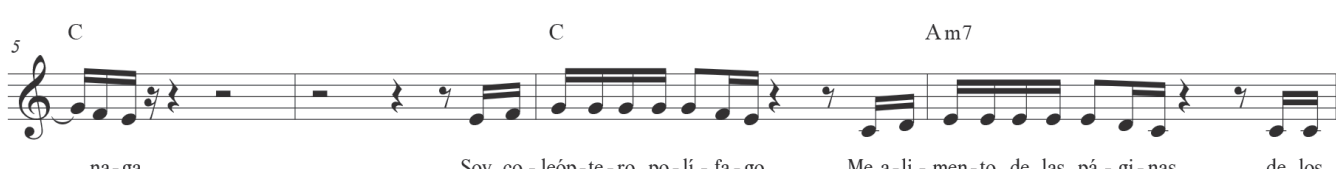

_ na-ga.

Soy co-leóp-te-ro po-lí - fa-go.

Me_a-li - men-to de las pá-gi-nas

de los
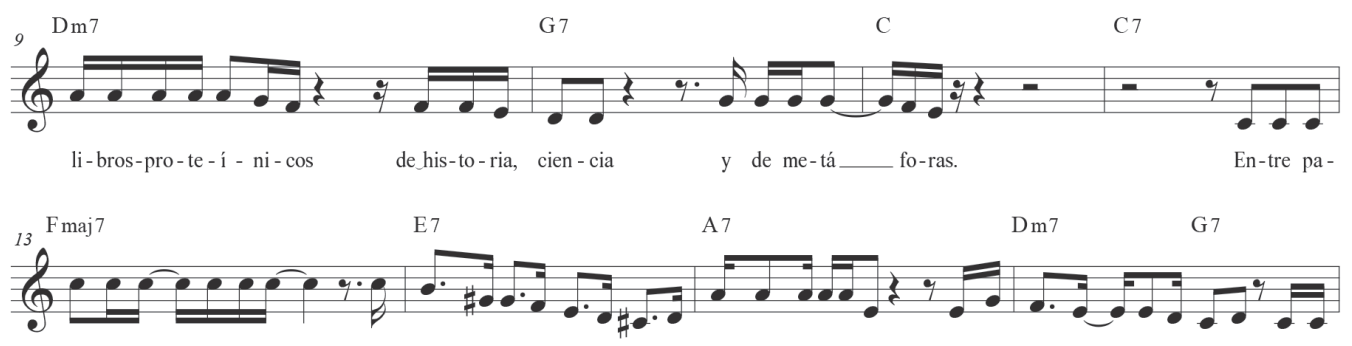

la-bras i - ma-gi-no_ que sur-co_un_u-ni-ver-so que se mi-de_en mi AD N, que ca-be en un_ so-lo ver so. Ca-da
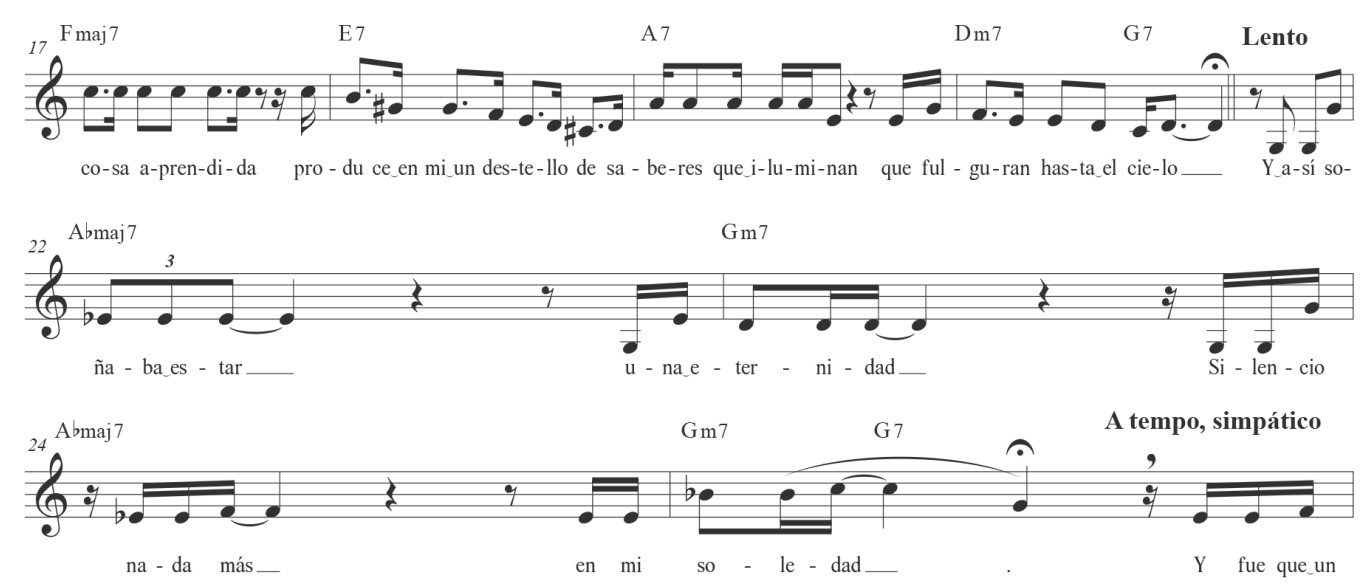


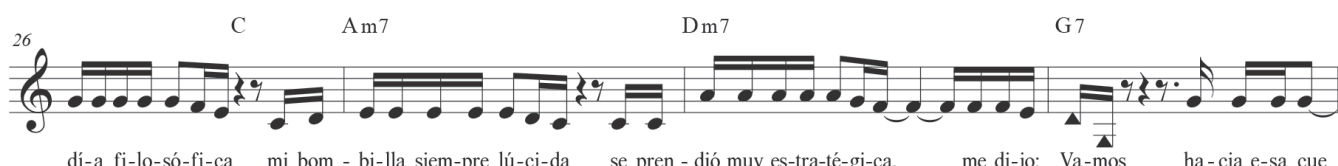

dí-a fi-lo-só-fi-ca mi bom - bi-lla siem-pre lú-ci-da

se pren - dió muy es-tra-té-gi-ca, me di-jo: Va-mos ha-cia e-sa cue (casi hablado)
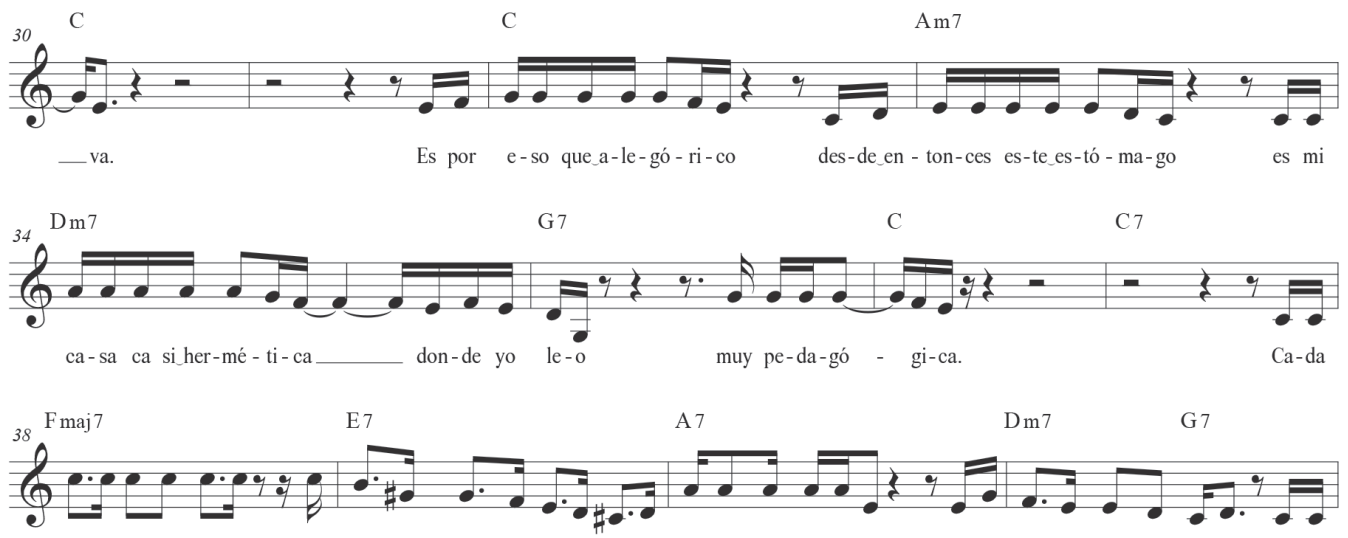

co-sa a-pren-di da pro-du-ce_en mí un des-te-llo de sa-be-res-que_i-lu-mi-nan, que a - u-llan has-ta_el cie-lo. En mi

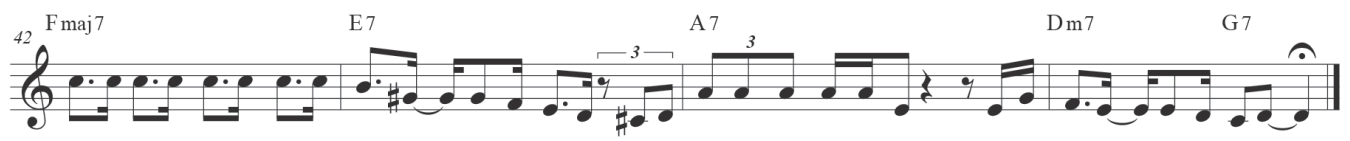

nue-vo a-po-sen-to nun ca na - die_ me mo-les-ta. Le-o cós-mi-ca_en el tiem-po

en $\mathrm{mi}$ lin-da_ bi-blio-te-ca. _

\section{A Max Góldenberg Guevara}

La canción de la Luciérnaga es una secuela atemporal o paralela de El vals del Coyote, canción de Max Góldenberg.

La luciérnaga-de la familia lampyridae- es un mítico insecto bioluminiscente que una vez un coyote -canis latrans- engulló porque no lo dejaba dormir tranquilo en su soledad.

\section{Daniel Solano}

Junio de 2018 